\title{
Preparation and Characterization of Nano-size Polyreactive Blue MXR
}

\author{
JOGHEE SURESH, RAJA GOPAL RAJIV GANDHI, SUNDARAM GOWRI, \\ SAMAYANAN SELVAM and MAHALINGAM SUNDRARAJAN*
}

Department of Industrial Chemistry, School of Chemistry, Alagappa University, Karaikudi-3, Tamil Nadu, India.
*Corresponding author; Tel/Fax: +91 9444496151 / +91-04565-225202
drmsgreenchemistrylab@gmail.com (M.Sundrarajan)

Received 16 September 2011; Accepted 25 December 2011

\begin{abstract}
Nanosize Polyreactive blue MXR dye was synthesized from reactive blue MXR dye in presence of potassium persulfate as catalyst. The formation of polyreactive blue MXR was indicated by colour change from blue to brown. The characterization techniques such as, Fourier transform infrared spectroscopy (FTIR), Atomic force microscopy (AFM), and X-ray diffractrometry (XRD) were used to characterize the formation of nanosize polyreactive blue MXR. The absence of asymmetric stretching of $\mathrm{NH}_{2}$ group in polymer dye FTIR spectrum confirmed the polymerization of dye was occurring. The average particle size of the polymer dye was found to be 18.11 $\mathrm{nm}$ according to Scherer formula. AFM analysis shows the three dimensional structure of polyreactive blue MXR.
\end{abstract}

Keywords: XRD, AFM, Reactive dye, Chemical oxidation, Polymer.

\section{Introduction}

Dye is a coloured substance, which used to colour the material ${ }^{1}$. Dyes and their complexes have found application in various fields such as textiles, bio-medicals, organic synthesis, lasers, liquid crystals display, electro optical devices and inkjet printers ${ }^{2-4}$. Dyeing are essentially process of colouring substances is usually taken to refer the colouring of various textile fabrics, but broadly speaking it is not limited to any defined materials. Synthetic dyes are widely used in textile and paper industries ${ }^{5}$. The textile industry is the largest user of synthetic dyes and consumes about $56 \%$ of the total annual world production $\left(7 \cdot 10^{5} \text { tons }\right)^{6-7}$. Among the available dyes, about $50 \%$ of the industrial dyes produced in the world are azo dyes. Reactive group of azo dyes are mostly used in textile dyeing due to their superior fastness to the applied fabric, high photolytic stability, and resistance to microbial degradation. However, reactive dyes exhibit low levels of fixation with the fibre and about 
$10-20 \%$ of total dye used in dyeing process is left in the spent dye bath with accessory chemicals $^{8,9}$.

Disposal of these dyes into the environment causes serious damage, since they may significantly affect the photosynthetic activity of hydrophytes by reducing light penetration and they may be toxic to some aquatic organisms due to their breakdown products ${ }^{10,11}$. To overcome this problem, recent studies included combinations of anaerobic and aerobic steps in an attempt to achieve not only dye decolourization but also degradation ${ }^{12}$. Coloured effluents from textile industries, pose a significant environmental pollution problem. Even at low concentrations, textile wastewater is intensely coloured. It has been reported that coloured effluents can be effectively degraded by ozonation ${ }^{13,14}$. The above problems avoided over a suitable support. In this study a method has been taken to prepare nanosize polyreactive blue MXR dye in order reduce the dye content in the effluent. When the nanosize is used in dyeing process the dye uptake was improved much more than that of ordinary bulk dye molecules. The size reduction of dye by polymerisation occurred without affecting chromophores. This approach has been reported with reactive dye containing amino group. In general size reduction of particles may led to changes in their physical properties. In polymerisation of dyes, the modification of reactive groups of dye occurred without involving the basic chromophores. In the present work nanosize polyreactive blue MXR was prepared by polymerisation in presence of potassium persulfate as catalyst. The synthesised nanosize dye was characterized by FTIR, XRD and AFM.

\section{Experimental}

\section{Materials}

Reactive blue MXR (Astik Dyestuff Pvt Ltd Tirupur), and potassium persulfate (FISCHER) were used as such.

Reactive blue MXR monomer solution was prepared by dissolving it in $1 \mathrm{M}$ hydrochloric acid. The polymerisation of monomer was carried out by adding the solution form of oxidising agent, potassium persulfate in dropwise to avoid the warming of the solution. Stirring was continued for three hours to ensure polymerisation of the dye. After 3 hours of stirring, the colour of the solution changed to brown within one minute by keeping the stirred reaction mixture at room temperature. On evaporating the brown colour solution, we get the powder form of polymerised dye.

FTIR, XRD and AFM characterization techniques were used to analyze the polymer dye. FTIR spectrum was recorded on a Perkin-Elmer 783 Spectrophotometer. AFM studies was done on diCPII Veeco USA model AFM. The computer controlled XRD system JEOL IDX 8030 was used to record the X-ray diffraction of dye sample.

\section{Results and Discussion}

\section{FTIR Spectroscopy}

The FTIR spectrum of reactive blue MXR (monomer) is depicted in figure 1A.The peak at $3436 \mathrm{~cm}^{-1}$ corresponds to the stretching vibrations of $\mathrm{NH}_{2}$ present in the dye. The symmetric and asymmetric vibration of $\mathrm{C}-\mathrm{H}$ occurs at 2358 and $2340 \mathrm{~cm}^{-1}$ respectively. The peak due to other stretching vibrations of $\mathrm{C}=\mathrm{O}$ of quinine ring and $\mathrm{C}=\mathrm{N}$ and $\mathrm{C}-\mathrm{Cl}$ of triazine moiety group corresponds to the peak at $1540 \mathrm{~cm}^{-1}, 1409 \mathrm{~cm}^{-1}$ and $619 \mathrm{~cm}^{-1}$ respectively. The bending vibration of $\mathrm{CH}$ in $\mathrm{CH}_{2}$ group exhibit the peak at $1390 \mathrm{~cm}^{-1}$. The symmetric and asymmetric vibrations of $-\mathrm{SO}_{3} \mathrm{H}$ corresponds to the peak at 1188 and $1105 \mathrm{~cm}^{-1}$. The 
spectrum of nanosize polyreactive blue MXR (polymer) is illustrated in figure $1 \mathrm{~B}$. The $\mathrm{N}-\mathrm{H}$ deformation vibration of amino group occurs at $1625 \mathrm{~cm}^{-1}$ and other characteristic peaks corresponding to the functional groups occur as such in the monomer.

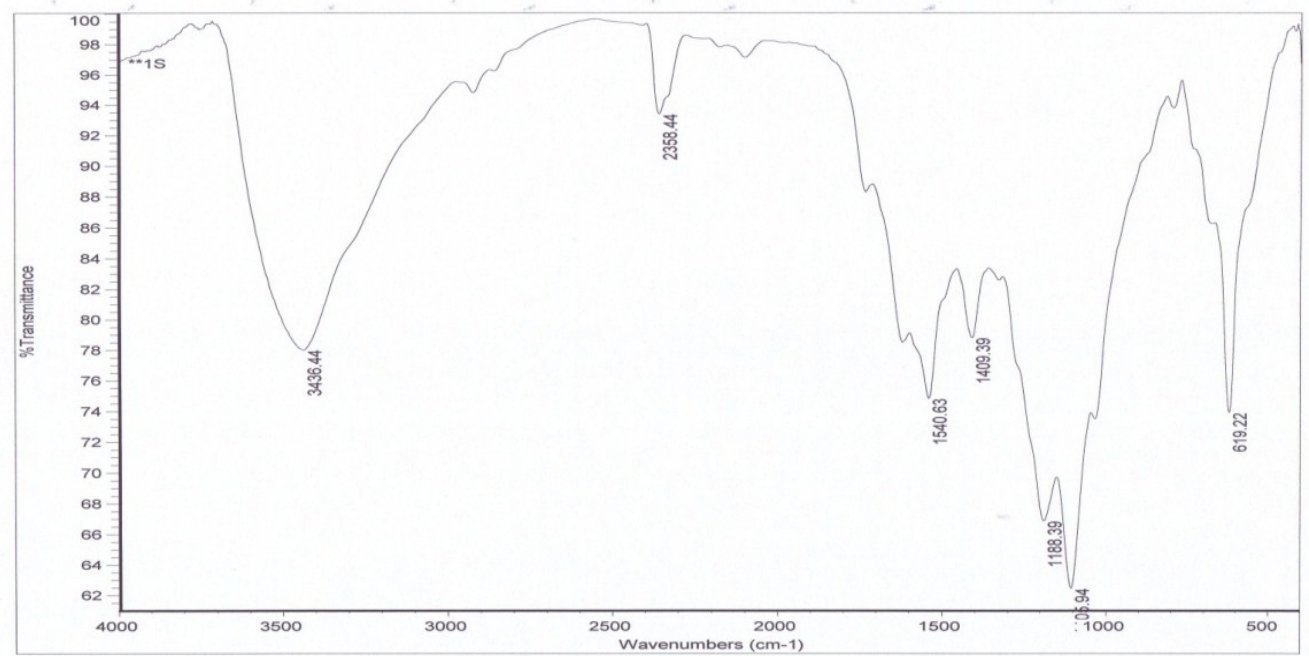

Figure 1 A.FTIR spectrum of reactive blue MXR.

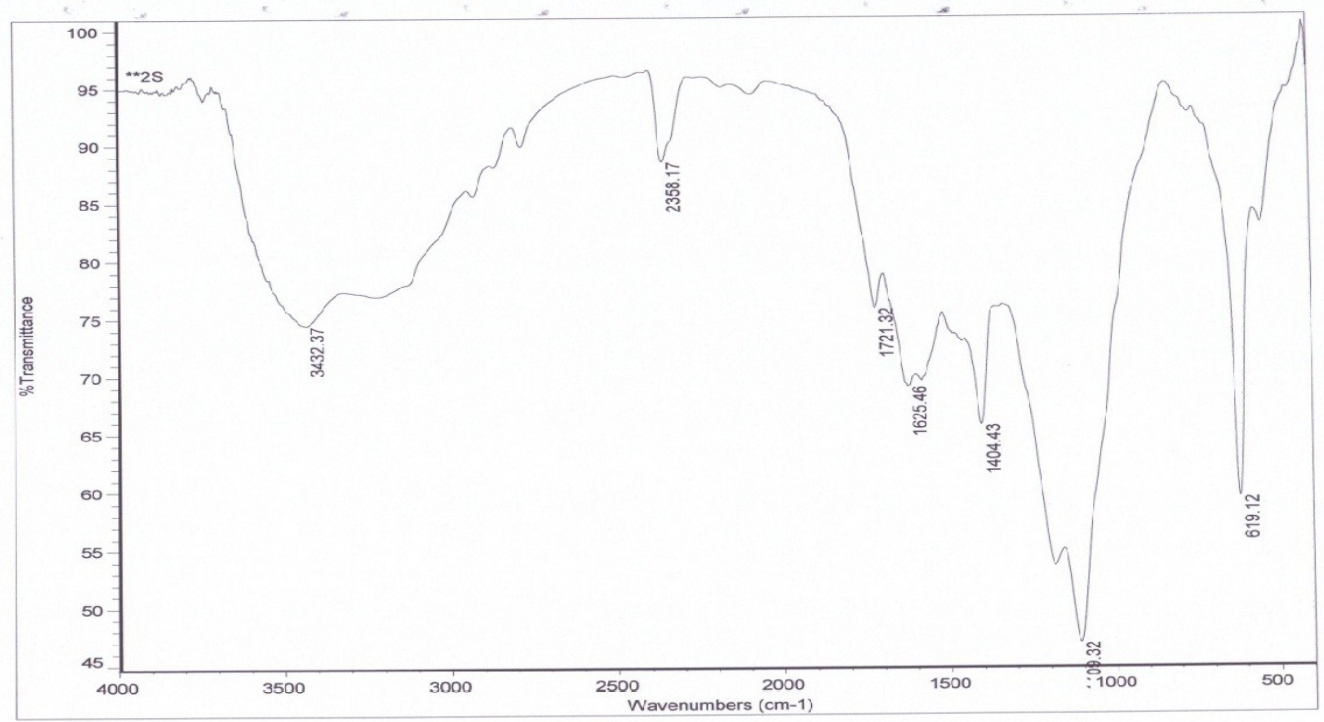

Figure 1B. FTIR spectrum of polyreactive blue MXR.

\section{$X R D$ and AFM studies}

The XRD patterns of the polyreactive blue dye are presented in Figure 2. It provides information about structures, phases, preferred crystal orientations (texture) and other structural parameters such as average grain size, crystallinity, strain and crystal defects. The 
sharpness and intensity of the XRD peaks specify the more crystalline nature of dye. The size of the polymerised dye calculated using Debye Scherer's formula. It can be give as follows.

$$
D=\frac{0.94 \lambda}{\beta \operatorname{Cos} \theta}
$$

where $D$ is the average crystal size. The mean crystallite size is $18.11 \mathrm{~nm}$.

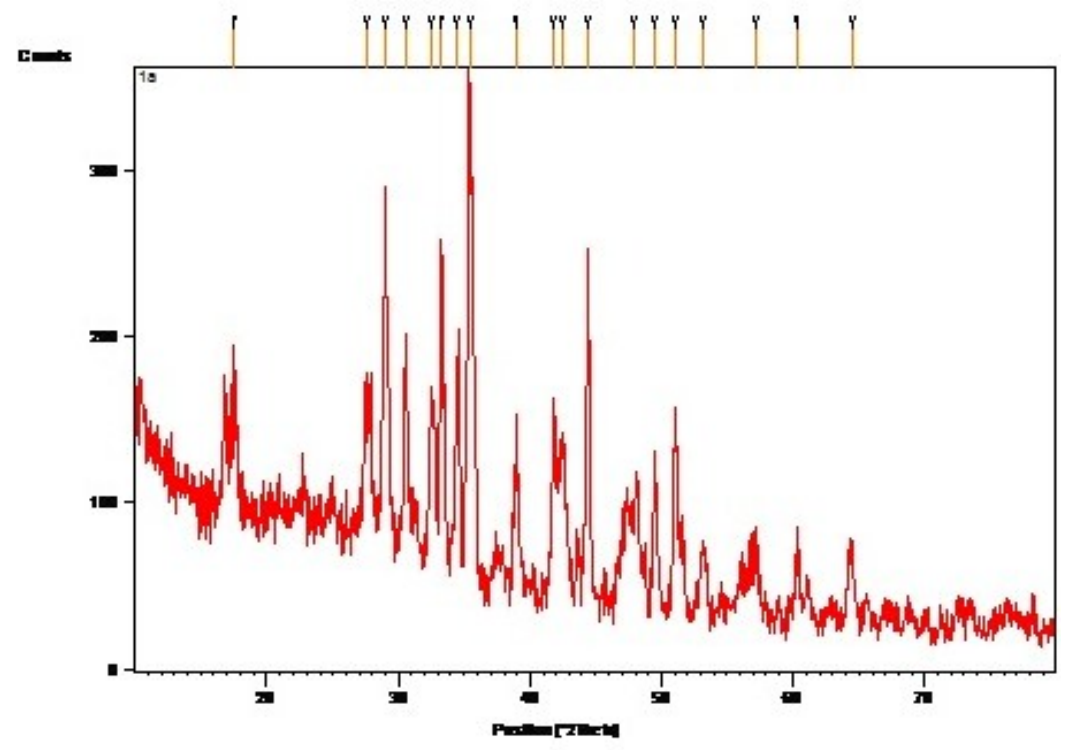

Figure 2. XRD spectrum of polyreactive blue MXR dye.
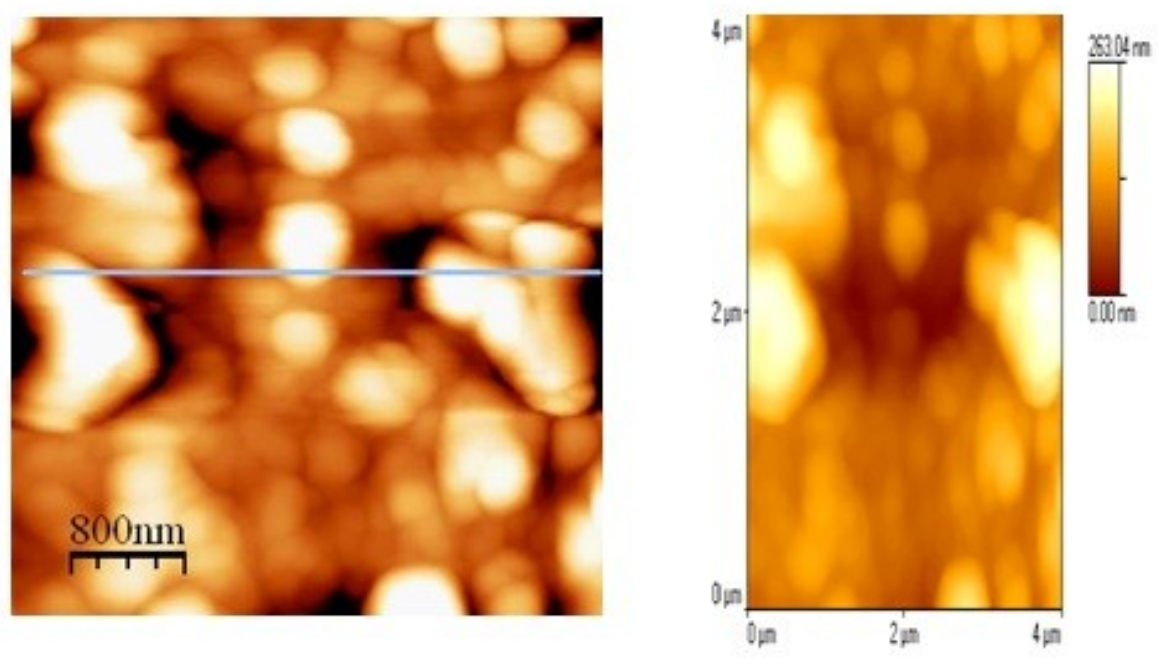

Figure 3. AFM image of 2D form of Polyreactive blue MXR dye. 
In this work, we used atomic force microscopy (AFM) to analyze polymer dye which is coated on glass plate. The 2D and 3D AFM images of polyreactive blue MXR are given in Figure 3 and 4.The height distribution is observed as $263.04 \mathrm{~nm}$ and $800 \mathrm{~nm}$ level in 2D and $3 \mathrm{D}$ form respectively. The average size of the nanoparticles is $160 \mathrm{~nm}$.
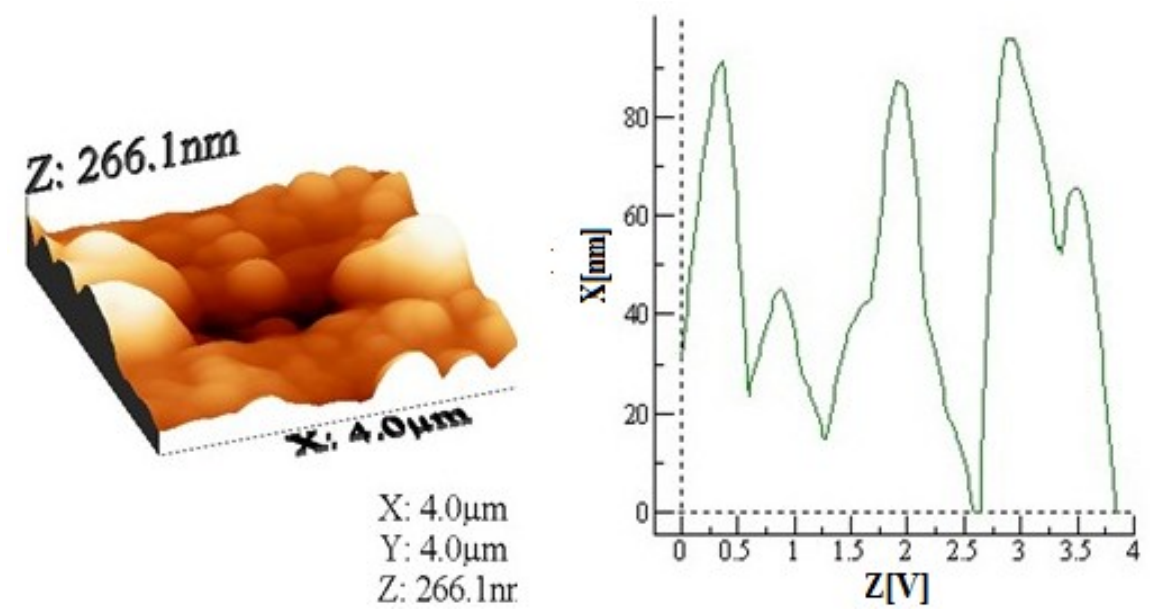

Figure 4. AFM and its line profile image of polyreactive blue MXR dye is in 3D form.

\section{Conclusions}

Polyreactive blue MXR dye was prepared from reactive blue MXR dye in acid medium by chemical oxidation method using potassium persulphate. Disappearance of N-H asymmetric stretching vibration in the FTIR spectrum of polymer dye illustrates the participation of amino group during polymerization of a monomer dye. X-ray diffraction studies revealed the formation of nanosize dye $(18.11 \mathrm{~nm})$. AFM analysis showed the three dimensional view of the nanosize reactive dye. These results showed that reactive blue MXR dyes are polymerized to polyreactive blue MXR dye. This nanosize polyreactive dye has several promising applications in textile technology.

\section{Acknowledgement}

The authors express sincere thanks to University Grant Commission (UGC), Government of India, New Delhi, for financial support.

\section{References}

1. Sujatha V B, Bhimson A N, Meenakshi S, Science., 2005, 840.

2. Peters A T, Freeman H.S, Colour chemistry, 1991, 193.

3. Gregory P, High-technology applications of organic colorants New York and London(1991).

4. Catino S C, Farris R E, concise encyclopedia of chemical technology. Wiley, New York(1985). 
5. Vinodgopal K, Peller J, Makogon O, Kamat P V, Water Res., 1998, 32, 3646.

6. Hutzinger O [Part A] The handbook of environmental chemistry, Springer-Verlag, Heidelberg, 1980, 3, 188.

7. Vaidya A A, Datye K V, Colourage., 1982, 14, 3.

8. Gouvea C A K, Wypych F Moraes, S G, Duran N, Nagata N and Peralta Z P, Chemosphere, (2000) 40, 433.

9. Murugesan K, Dhamij A, Nam I.H, Kim Y.M Chang Y S, Dyes Pigments, 2006, 75, 1.

10. Aksu Z, Kilic N.K, Ertugrul S, Donmez G, Enzyme and Microbial Technology, 2007, 40, 1167.

11. Hao O J, Kim H, Chiang P C, Critical reviews in Environmental Science and Technology 2000, 30, 449.

12. Lodato A, Alfieri F, Olivieri G, Di Donato A, Marzocchella A, Salatino P. Enzyme Microb Technol., 2007, 41, 646.

13. Hitchcock D R, Law S E Wu J, Williams P L, Arch Environ Contam Toxicol., 1998, 34, 259.

14. Wu J, Wang T, Wat Res., 2001, 35, 1093. 


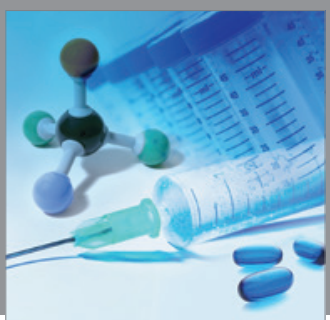

International Journal of

Medicinal Chemistry

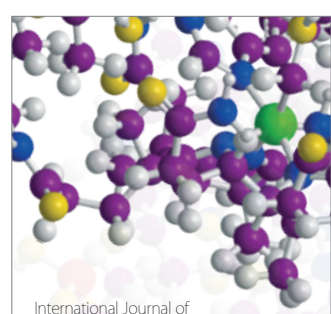

Carbohydrate Chemistry

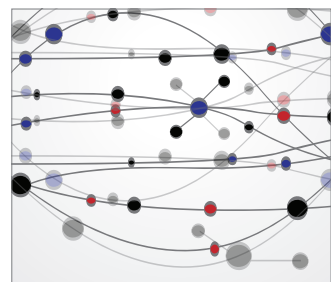

The Scientific World Journal
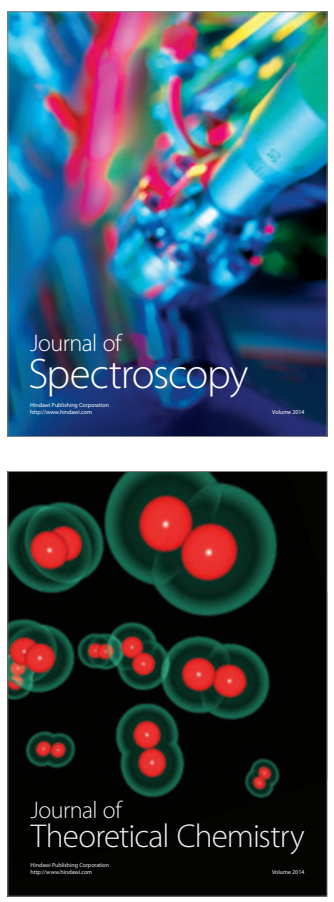
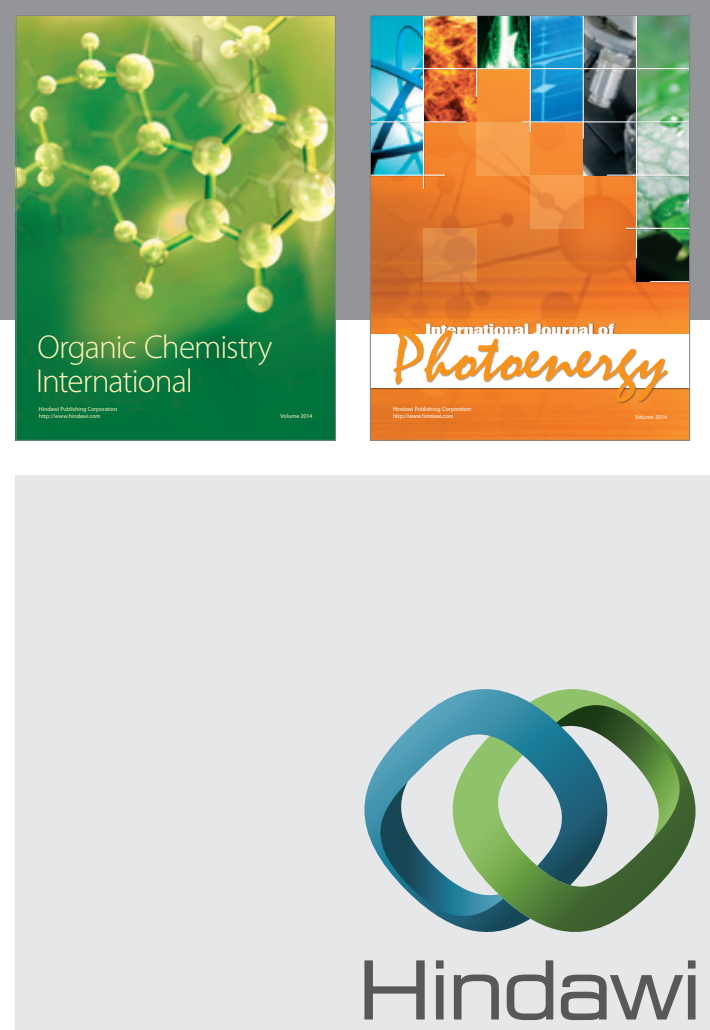

Submit your manuscripts at

http://www.hindawi.com
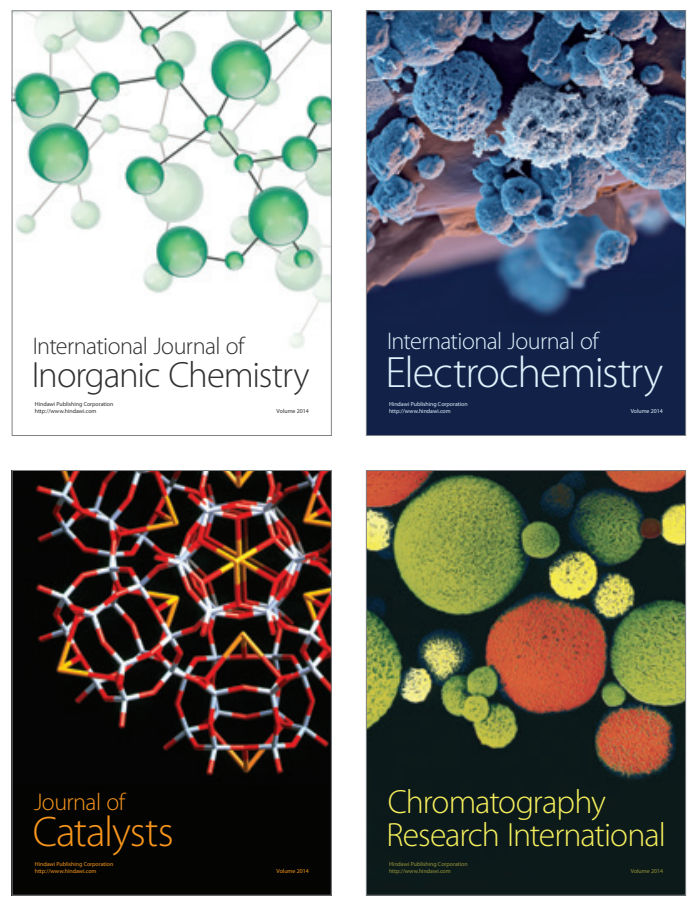
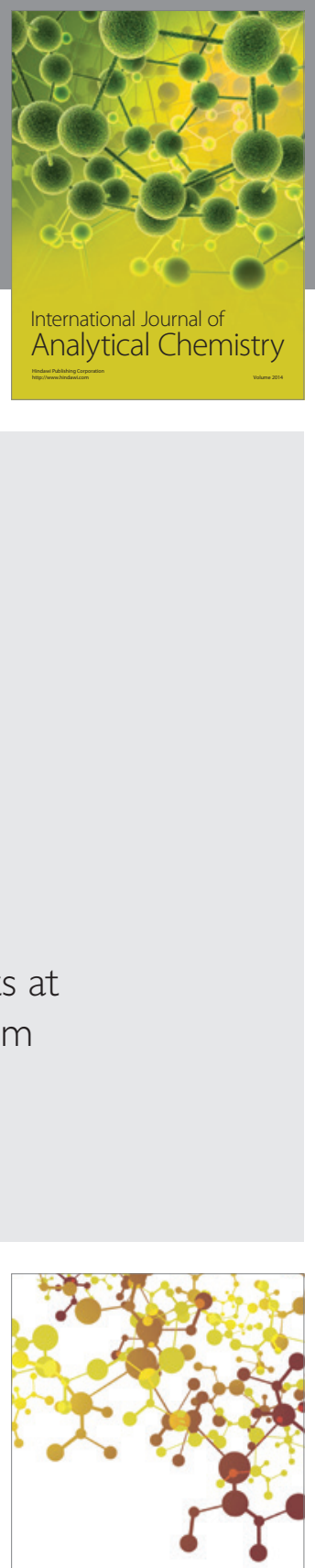

Journal of

Applied Chemistry
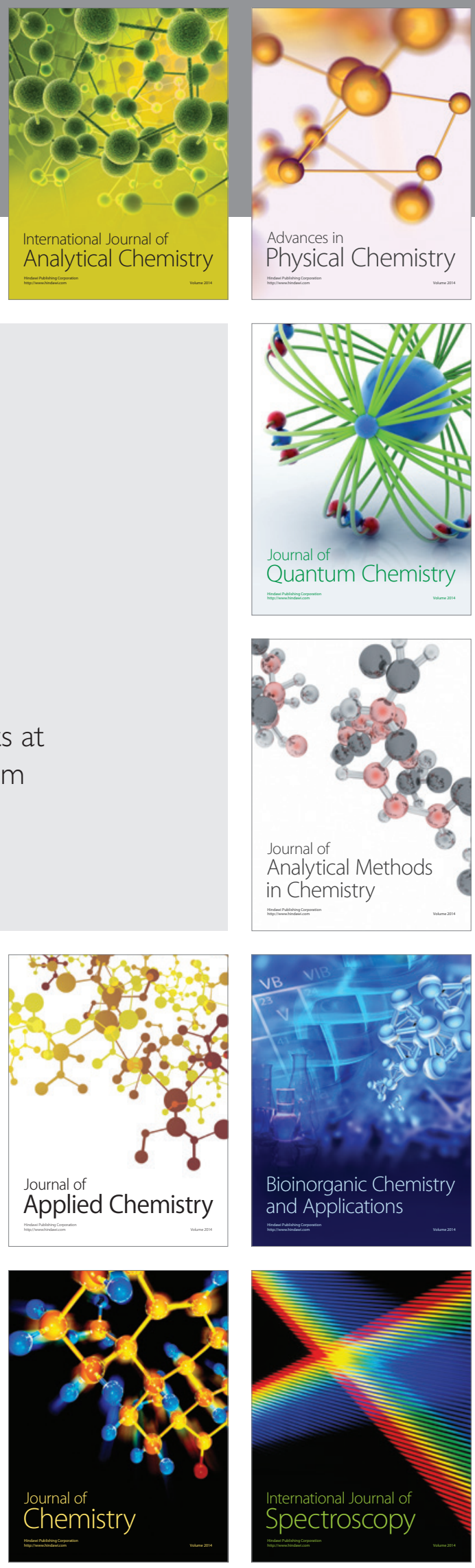